$\xi=-1$

\title{
The Effectiveness of Ict in Edifying Language Learning: a Quasi -Experimental Study
}

\author{
Mohankumar S ${ }^{1}$ Dr.V.Vijayalakshmi ${ }^{2}$ Manjusha $C^{3}$ \\ ${ }^{I}$ Research Associate, Division of English, SAS-SSL, VIT University, Chennai \\ ${ }^{2}$ Assistant Professor, Division of English, SAS-SSL, VIT University, Chennai \\ ${ }^{3}$ Research Associate, Division of English, SAS-SSL, VIT University, Chennai \\ *Corresponding author E-mail: mohankumars0211@gmail.com
}

\begin{abstract}
Technological development is bringing in tremendous changes in almost all the arenas. Educational needs of today are not like those days where traditional practices served the purposes. ICT and e-learning is replacing the educational systems. In such a scenario, students are to be aware of the better platforms to equip themselves with the recent trends and changes. The objective of this research paper is to enthrove how effective will be the process of learning if ICT is implemented in the classrooms. Activities based on ICT focusing on enhancing writing skill are the core of this research paper.
\end{abstract}

Keywords: Creative writing; Education; Emotional state; ICT; Language learning; Writing skill.

\section{Introduction}

India stands for its multi culture and multi language which has ancient traditions and histories. This nation blessed and bridged with English language. India has large number of youths than any other countries. As per census conducted in the year 2011, the ratio of youth population is one-fifth of India's total population. This represents and demands the need for changes and revolution in all the sectors. Technology dominates the $21^{\text {st }}$ century and came with an idea of digital natives. Especially in the educational sector, ICT (Information Communication and Technology) emerged as an omnipotent power. Every education institutions celebrate and accept this trend and feel proud to have language laboratories and smart classes. It swiftly shifts from Gurukula system to Google era. The research article titled "Is print readers declining? A survey of Indian online newspaper readers" discussed the interest of young people towards online reading (Tewari). This research paper concentrates and highlights the role of ICT in developing the emotive writing skills of college students. The ICT era offers and creates the opportunity to share their writing in various online platforms.

\section{Aim and Scope}

Last decade faces many changes in language classrooms, it reflects both in learning and as well as in teaching. It makes the learning process feasible and encourages out of box thinking. This paper focuses on how ICT helps the students to use the chances effectively and how the language teachers can help the students to develop them in different arenas. It discussed about the learning experience of students in ICT era. This research narrow down and concentrates on how ICT paves a path to attain good writing skill among students. This paper is based on a study conducted among students in particular span of time.

\section{Ict and Language Learning}

ICT is a revolution in Educational field, when it comes for language learning; it breaks all the barriers and reframes the all traditional ideas and beliefs. It helps to learn and use language in both formal and informal way. The language classrooms turned as language labs with all digital equipments like headphones, mike, software, eBooks, LED screens, audio and video lesson plans. Teachers change themselves as trainers and mentors. Students also use social networks like Facebook, blogs and other online resources for education and as well as entertainment purpose. ICT allows students to share their experience and knowledge without any restrictions. The classroom assignments also upload in Moodle and encourage the online learning among students. High level of communication is take place in online learning than traditional teaching/learning. The ICT era encourages and compels the student for active participation. They write or speak to have a touch with online platforms. This kind of communication helps them to learn and understand the language in good level. Wide range of reading and writing is the essential thing for language learning. Recent days, all literary and other works in various languages are converted and uploaded in digital format for world level recognition and usage. ICT act as a preserver of all languages, it makes language learning with deep understanding and lot of opportunities.

\section{Review of Literature}

A study should have good review of literature to identify the areas discussed in previous studies and research gap. It helps to strengthen the research and arguments of present study.

"Barriers in using technology for education in developing countries" (R.C. Sharma), discussed about the learning needs of children and youths in developing countries. He talked about both 
formal and informal education. In this article, he clearly mentioned about funding problems, knowledge of teachers, government policies and issues between different sectors. He came up with various suggestions like using FM radios, TVs, and teleconferences.

"ICT in Indian universities and colleges: opportunities and challenges" (Neeru Snehi), this article explained about major transformation in various aspects of higher education and its influence. It argued about key issues like access, efficiency, pedagogy and quality in educational stream. The research addresses the opportunities and challenges in ICT and then it describes about policies and strategies.

"ICT enabled language learning using hand phones-An experimental study" (J.Samuel Kirubahar, et.al), this research article discussed about how to enhance the quality in higher education through ICT, then it explained about current pedagogy in the society and job opportunities. It highlights the role of learner-centered classrooms and practical learning. This paper focused on successful implementation of ICT in educational system.

"Role of ICT in English language teaching" (Saritha Samuel \& Rashmi Pulizla), this article explained about traditional teaching and its problems. Then it describes about various techniques in language teaching and learning. It focused on implementation of technology in English language teaching and how it can be used to develop the four basic skills in language.

"The use of information and communication technology (ICT) in teaching writing skills" (Melor Md Yunus), this article highlight the lack in encouraging writing skills using ICT. This paper is based on the data collected from four schools in Kuala Lampur. It discussed about how ICT can be used to develop writing skill among students, and then it came up with suggestions for Ministry of Education in Malaysia.

\section{Population Chosen}

This research paper is based on the study conducted among 60 students. It consists of 35 boys and 25 girls from arts and Science College in Tamil Nadu, India. The reason for choosing this population is students are mostly first generation students and from rural background. This kind of study helps to create awareness among those students about learning possibilities in ICT and its era.

\section{Methodology}

This study based on qualitative approach. It helps to explore the problems and understandings of students in language learning through ICT. It concentrates on emotive writing skills of students. Emotive writing deals with culture, behaviour, intrapersonal and interpersonal relationship of students. Qualitative study helps to understand the nuances in emotional state of students and its connection with language and writing.

\section{Problems Faced by Students in Traditional Classrooms}

The personal informal interviews and focus group discussions helped the researcher to understand the experiences and perceptions of students about traditional classroom and the teaching methodology. Especially, in writing, students become very conscious about the errors that may occur in grammar, sentence structure and other traditional rules. Moreover, they have a feeling of hesitation to show their written work to the teachers and their peer group. Though written well, they have a kind of shyness and inferiority complex. This problem is very high among the introvert students. They find things boring in traditional way of corrections and they wish to have student centre practices or activities rather than getting corrections for better performances.

Apart from their classroom issues the researcher also enquired about their knowledge, awareness and understanding towards ICT. Students from rural areas and those from poor economic background do not have much awareness towards the development and use of ICT. They do not have the opportunity to join the flow of ICT era. Their knowledge is limited with a few social networks like Facebook, twitter and whatsapp. Most of the students do not know to make use of the apps in the smart phones for educational purposes.

\section{Ict in Classroom Activities}

After understanding the needs of the students, the researcher carefully implemented the activities in English classroom to develop their writing using ICT. Writing in initial stage needs lot of practices and freedom. Based on this idea, the researcher introduced the "blogger" in the classroom.

\section{Research Profile}

The research was carried on in three phases. In the first phase, the researcher asked the students to write about themselves in any form of writing. Students were given freedom to choose the different genres to write like poetry, verses, Para verses, excerpts, short stories etc., in this stage, researcher kept the focused group of respondent's busy writing in the blogs. Following this, the students were asked to give comments to the post and they were restricted to give only positive comments.

The students were then asked to create a group in any social media and they chose whatsapp as it was available with all the 60 respondents. A group with 61 members including the researcher was created. Activities based on their daily works, likes and dislikes and so on was assigned by the researcher. The respondents participated with much interest and said these activities helped them to enrich their vocabulary.

In the second phase, the students were introduced to online platforms and mobile applications for writing purposes. As the students hesitated in the beginning to write in the open platforms, they were asked to use pseudo names and this was encouraged by the students. In this phase, online reading and writing platforms were introduced to the students and were assisted in becoming members of the online libraries and other sources like poetry hunter, poetry world, and edutopia and so on. Respondents submitted their writings through such online forums and this helped in understanding their interests and the impact of ICT.

In the third phase, the participants were introduced to creative writing and they were considered the advanced level learners. In this stage, they were given freedom to choose the themes and kind of writing as they wished but they were given time limit. The respondents improved their style of writing with the cozy lucid terms, correct sentence structures, logical arrangements and brilliant choice of themes. All these phases of research gave importance not only to the writing skills but also in developing emotional state of mind and well being.

\section{Opinionnaire Collection}

After the activities, Opinionnaire collection was done. The students had the chance to state their opinions frankly. They stated that smart classrooms never allowed them to access any online platforms in the classroom. They were able to make use of the pre installed software and not otherwise. But through these activities, they gained much knowledge about the various educational platforms. They have pointed

1. They were able to overcome shyness and emotional obstacles 
2. They were able to reach larger audience and readers through online writing

3. They were able to equip themselves with the recent trends in writing.

They have also mentioned they are happy to see their transformation. They are ready to enhance their language skills in innovative ways using ICT.

\section{Challenges in Introducing Ict}

The educational institutions in the rural areas do not have the opportunities to implement ICT at full stretch. Language labs in such colleges are known only for repeating the same exercises with no productive results. Though internet connection is provided, many educational websites are blocked. Efforts have to be taken to ensure ICT reaches the nook and corners of the world equally so that education is enjoyed by all.

\section{Conclusion}

ICT is a boon for language learning process. In developing countries like India, rural areas are often forgotten and they are not provided with the basic technological developments. This research article is an attempt to bring out how effectively ICT can be used in the process of language learning especially among the rural college students. It is the right time to think about employing technology in the process of learning and enhancing language skills. ICT oriented activities serves the dual purpose of improving language skills and monitoring the emotional problems of the students and helping them overcome the same. If used properly, ICT inculcates human values, moral deeds and educational needs in the most thoughtful manner.

\section{References}

[1] http://mospi.nic.in/sites/default/files/publication_reports/Youth_inIn dia-2017.pdf

[2] Tewari P (2016). Is Print Readers Declining? A Survey of Indian Online Newspaper Readers. J Socialomics 5:177. doi:10.4172/2167-0358.1000177

(https://www.omicsonline.org/open-access/is-print-readersdeclining-a-survey-of-indian-online-newspaper-readers-2471-87261000177.php?aid=76877\&view=mobile)

[3] http://ieeexplore.ieee.org/abstract/document/1270670/

[4] Neeru Snehi (2009), "ICT in Indian Universities and Colleges: Opportunities and Challenges", Management \& Change, Volume 13, number2 (2009)

[5] J. Samuel Kirubahar, A. Subashini, and V. Jeya Santhi. ICT Enabled Language Learning Using Handphones - An Experimental Study. Language In India Volume 11 : 3 March 2011 ISSN 1930-2940

[6] Saritha Samuel, Rashmi Pulizala. Role of ICT in English Language Teaching. IJIRD, November, 2014 (Special Issue) Vol 3 Issue 12. ISSN $2278-0211$

[7] Melor Md Yunus1, Norazah Nordin1, Hadi Salehi1, 2, Mohamed Amin Embi1 \& Zeinab Salehi2. English Language Teaching. ISSN 1916-4742 (Print) ISSN 1916-4750 (Online) 